\title{
Book Review---Giuseppe Balirano, Maria Cristina Nisco (eds.) 2015 Language, Theory and Society: Essays in English Linguistics and Culture, Liguori, Napoli.
}

viii + 231 pp ISBN 978-88-207-6605 (paper)

eISBN 978-88-207-6606 (eBook)

$€ 28.99$

Reviewed by:

Girolamo Tessuto ${ }^{1}$

${ }^{1}$ Associate Professor of English, Linguistics and Translation, Seconda Università degli Studi di Napoli, Università degli Studi di Napoli Federico II, Director of Centre for Research in Language and Law (CRILL), Italy

Correspondence: Girolamo Tessuto, Associate Professor of English, Linguistics and Translation, Seconda Università degli Studi di Napoli, Università degli Studi di Napoli Federico II, Italy

Received: December 14, 2015

Accepted: February 20, 2016

Online Published: March 2, 2016

doi:10.5430/elr.v5n1p11

URL: http://dx.doi.org/10.5430/elr.v5n1p11

In today's interconnected and globalised world, understanding issues related to the forms and structures of discourse, talk, text, or communication and the relationship of these to social and cultural representations is both a personal and intellectual endeavour, and becomes a focal point for making discourse an interdisciplinary field of study that lies at the crossroads of language, culture and society. Although many academic disciplines are engaged with discourse as an important theoretical and empirical focus for their inquiries, the interest in discourse for us pursuing the goals of (applied) linguistics reaches out further than language itself, and extends to "language use relative to social, political and cultural formations [...], language reflecting social order but also language shaping social order, and shaping individuals' interaction with society" (Jaworski and Coupland 1999: 3). This interest is readily apparent from the myriad of discourse-related works published recently, such as those dealing with national identity (Wodak et al. 1999), ideologies (Schäffner 1997), discourse and politics (Howarth et al. 2000), professional discourse (Gunnarson, Linell, Nordberg 1997), professional communication across cultural boundaries (Scollon, Scollon, Yuling 2001), and translation (Schäffner 2002), to mention just a few. At the same time, this kind of engagement brings out important theoretical insights and works with a variety of discourse analytical models where texts are examined for language use, communication and interaction (van Dijk 1997), social events (texts), social practices (orders of discourse), and social structures (Fairclough 2003) alongside ideology and power patterns of social systems and institutions embedded in the forms of language (van Dijk 1997; Fairclough 1995, 2003), or ideological underpinnings of social practices in various semiotic modes - visual, verbal, gestural (Kress and Van Leeuwen 2006 [1996]), to name again only a few theoretical orientations.

Within this framework, Language, Theory and Society: Essays in English Linguistics and Culture edited by Giuseppe Balirano and Maria Cristina Nisco stands out. It is one of the most recent book-length publications in English linguistic scholarship, and provides a cutting-edge map of an interdisciplinary avenue relevant to the study of discourse in social life. Through the voices of its contributors from different, yet contiguous, research interests, the book takes a discourse-centred approach to language, society and culture in a fairly wide range of topics and scrutinises "current approaches to the linguistic, cultural and social interpretation of texts in diverse contexts of English" (p. vii). It is a well written, highly accessible book - Balirano and Nisco are well aware of their material in hand, and present it in a way that combines fervor and exhilaration with critical insights for the wider readership. With a number of works on the market investigating social and cultural processes from a linguistic/discourse-analytic point of view, and with a growing number of edited volumes providing an invaluable overview of the subject, the burden was very much on this published volume to come up with a fresh outlook. And I have no shadow of a doubt that it does just that as a cursory look at a straightforward and lucid statement by the editors will also confirm as regards the purpose of the volume, which is "to bring to the fore a variety of social and cultural representations and 
to illustrate the way in which represented participants are generally embedded in social, political, and cultural practices through and in the language" (p. vii).

With this purpose at work, the book takes the reader on a topical journey through theoretical and research developments in the topic areas of inquiry relevant to better understand our complex social environment. In doing so, the book comprises nine chapters showcasing studies that examine several different forms and structures of discourse and the way these are framed and organised in socio-cultural and socio-interactional contexts of language use, and gives a comprehensive account of the field in a variety of semiotic resources - linguistic-discoursal as well as multimodal. The chapters rely on qualitative and quantitative research paradigms for descriptive and interpretive analyses of data gathering, and draw their inspirations from a range of international theoretical principles in support of the empirical investigations under focus, noticing patternings of language in use and the circumstances (participants, situations, purposes, outcomes) with which these are typically associated in broader discursive contexts. This way of paying attention to text (language in use) and regarding the broader context of use as central (the setting, situation or knowledge available to the discourse participants contextualizing texts) brings to the sample of papers in the chapters experimental rigour in the accounting of socio-critical issues such as identity, power, ideology and culture, and the way these allow for the contextualized negotiation of social relations and action in discursive representations.

With these key issues being focused upon, individual chapters work within their specific methodological frameworks or a combination therein, ranging from multimodality, (critical) discourse analysis, corpus linguistics, pragmatics, (audio-visual), translation to literary and cultural studies, and consequently incorporate both linguistic (micro level) and social analysis of discourses as communicative events alongside the linguistic manifestations of discursive practices embedded within social systems and structures. For the reader to have a flavour of research topics being dealt with and the diverse methodological approaches taken by contributors across the volume, the editors weave a tight thread through the topical development of the chapters. Giuseppe Balirano (Ch. 1) looks at the construction of identities in advertising from the multimodal discourse analysis perspective and brings to his study an essential combination of theorising and broad communicative metafunctions realised by images and other social semiotic systems. Maria Cristina Nisco (Ch. 2) addresses the hot topic of Mediterranean migration in the British press using a corpus-based discourse analytical approach; Eleonora Esposito (Ch. 3) offers a critical study of political discourse in election campaigns; Stefania D'Avanzo (Ch. 4) analyses 'war on terror' discourse from a semantic and pragmatic perspective; Emilia Di Martino (Ch. 5) explores the relationship between translation and power across languages and cultures, Marta Cariello (Ch. 6) focuses on the translation of a literary text through the lens of cultural and postcolonial studies; Serena Guarracino (Ch. 7) studies the ways of performing national identity in literary, theatrical and musical elements of text; Bronwen Hughes (Ch. 8) examines the issues behind the transferral and translation of televised format productions; and finally, Angela Zottola (Ch. 9) examines the issues of identity, hybridity and power discourse in audio-visual translation. Crucially, the existence of distinctive analytical approaches and the variety of topics have their own benefits in that they infuse the book as a whole with an eclectic tenor while also providing fertile grounds for lively debate and charting further development in the ongoing research practices. While the use of 'back matters' (i.e. extensive lists of compelling references at the close of each chapter and accuracy of index at the end of the book) contribute to maximizing the benefits gained from the use of qualitative/quantitative data in the approach to linguistic, social and cultural studies of text and discourse, the contributors' familiarity with the chapters equips them with a sound level of engagement with the specific issues canvassed and objectives achieved. On this point, I do feel that the editors themselves plead a convincing case that "[e]ach chapter provides detailed reading of a particular text or event" (p- viii).

In spite of getting down to the nitty-gritties of actual text in coherent methodologies and evidence-based analysis of the conditions of production of such a text for social understanding, I do find it rather surprising that the volume makes no use at all of a chapter 'overview' in the Foreword or reference to a proper 'list of authors' working on the breadth of the topics beyond simply setting out which contributions do qualify for authorship as I found at the front in the 'list of contents' section. Although the editors are silent about the reasons for this omission, I can only assume that it comes down to the very nature behind the book aiming initially at a graduate-level student readership engaged with language and communication more generally. Whether this is the case, then, the inclusion of a chapter overview could well have provided the reader with the overarching content of research and similarly saved time by preventing the reader from having to actually read through and filter the important information. By the same token, and this is no less significant, listing authors in the volume could have accurately reflected who did the work by providing greater transparency to authors' research merit along the major ethical principles of academic publishing, and most 
importantly discouraged what appear, as it were, to be 'phantom' authors who qualify for authorship but are not listed throughout the volume.

Despite these inconsistencies that should not be lost sight of, I was delighted to go through the book and to assess its excellent quality on different accounts I have intended to unpack in these pages. The volume is an ambitious addition to the cross-fertilization of literature on the subject, and puts the contributors' own distinctive stamp on their studies originating from their own research experience. By exploring the complexity of language and discourse in a variety of texts and genres and the way they are mobilised in socio-cultural contexts and communicative practices, the volume not only brings into focus the range, depth and richness of current research in the field but also inspires new, illuminating work by providing scholars from diverse communities of practice (linguists, discourse analysts, researchers in professional communication, translators, and so on) as well as students seeking to pursue research work in Linguistics with state-of-the-art discussions of key aspects of this burgeoning field. Beyond the informative value of the book, Balirano and Nisco have worked hard and put together an interesting variety of takes on key issues confronting 'real-world contexts' and the 'actors' who live in them making this an enjoyable and intellectually stimulating read.

\section{References}

Fairclough, N. (1995). Critical Discourse Analysis: The Critical Study of Language. London: Longman.

Fairclough, N. (2003). Analysing Discourse. Textual Analysis for Social Research. London: Routledge.

Gunnarson, B., Linell, P. \& Nordberg, B. (1997). The Construction of Professional Discourse. London: Longman.

Howarth, D., Norval, A. J., Stavrakakis, Y. \& Laclau, E. (eds.) (2000). Discourse Theory and Political Analysis. Manchester: Manchester University Press.

Jaworski, A. \& Coupland, N. (1999). The Discourse Reader. London: Routledge.

Kress, G. R. \& van Leeuwen, T. (2006 [1996]). Reading Images: The Grammar of Visual Design. London: Routledge.

Schäffner, C. (1997). Analyzing Political Speeches. Clevedon, UK: Multilingual Matters.

Schäffner, C. (2002). The Role of Discourse Analysis for Translation and Translator Training. Clevedon, UK: Multilingual Matters.

Scollon, R., Scollon, S. W. \& Yuling, P. (2001). Professional Communication in International Settings. Oxford: Blackwell.

Van Dijk, A.T. (1997). Discourse as structure and process of discourse studies: A multidisciplinary introduction. Volume I. SAGE Publications, London.

Wodak, R., de Cillia, R., Resigi, M. \& Liebhart, K. (1999). The Discursive Construction of National Identity (trans. A. Hirsch and R. Mitten). Edinburgh: Edinburgh University Press. 